Journal of Life Economics

Cilt / Volume 6, Say1 / Issue 4, 2019, pp. 413-420

E - ISSN: 2148-4139

URL: https://www.ratingacademy.com.tr/ojs/index.php/jlecon

DOİ: https://doi.org/10.15637/jlecon.6.025

Araştırma Makalesi/Research Article

\title{
THE EXPORT DETERMINANT OF SOCIO-ECONOMIC RESILIENCE IN FOREIGN ECONOMIC ACTIVITY
}

\author{
Serhii BURLUTSKYI * \& Svitlana BURLUTSKA ** \& Tamara BEREZIANKO *** \\ * Doc.Sc. in Economics, Associate Professor, INGO " Save the Children International in Ukraine", \\ M\&E Officer, UKRAINE, e-mail: magistrdr@gmail.com \\ ORCID ID: https://orcid.org/0000-0003-0157-2564
}

** Doc.Sc. in Economics, Associate Professor, National University of Food Technologies, Professor of the Department of labour economics and management, UKRAINE ORCID ID: https://orcid.org/0000-0002-9497-7917

*** Doc.Sc. in Economics, Associate Professor, National University of Food Technologies, Head of the Department of labour economics and management, UKRAINE

ORCID ID: https://orcid.org/0000-0001-9228-4239

\begin{abstract}
An undoubted advantage of the diversified economies is their less sensitivity to dynamics fluctuations of local sectors and shock destructions. A downturn in one industry can be compensated by growth in another. Formed in Soviet times significant industrial potential of Ukraine was not possible to implement only in the national economy. A significant part of Ukrainian manufacturing and extractive industries products was consumed by foreign consumers. Formed absolute and relative advantage in international trade ensured the enrichment of a limited set of stakeholders and have become the drivers of system economic crisis and the loss of Ukraine's ability to adsorb (to leap back) shock disturbance. The results of the analysis indicate the negative impact of resources specificity on the Ukraine's ability to ensure sustainable development. Proved the validity of conclusions about the negative effects of high exports concentration (low commodity diversification) on the economy's response from shock disturbances.
\end{abstract}

Keywords: export determinant, socio-economic resilience, concentration, diversification, structural shifts.

Jel Codes: C62, F14, F44 


\section{INRODUCTION}

The obvious advantage of diversified economies is that they are less sensitive to fluctuations in the dynamics of specific industries and shock disturbances. A decline in one industry may be compensated by growth in another, which ensures the stability of the economy as a whole. It also contributes to the formation of effective employment: smoothing out shocks in certain sectors; formation of a more flexible labor market due to the inter-sectoral overflow of the labor force. Different degree of elasticity of demand and supply of certain industries, differences in the export orientation of industries, imbalances in capital and labor force (in general, diversification of economic structures) should hypothetically not only provide less vulnerability of the socio-economic system to shocks, but also higher rates of recovery from the shock. A system with a specialized economic base will be more receptive to certain (inherent to the dominant industries) shocks and will have less opportunities for reorientation. Practically, the diversity of alternative ways of economic recovery depends on the specifics of the existing specialization. Thus, the dominance of the extractive industry will have a different impact on the resilience of the socio-economic system in comparison to, for example, the superior hightech sector. The system of structural shifts is considered to be a specific factor in the dynamics of the efficiency of the socio-economic system. The main indicator of the effectiveness of the economic structure is the maximization of the national product or, in the case of regions, the gross regional product. The formation of the national (regional) product is the result of: firstly, the existing structure of output (composition and proportions between industries); secondly, the direction and structure of investment; thirdly, internal and external demand. Ukraine's considerable industrial potential, which had been formed in the times of the USSR, could not be used only within the national economy. A significant part of the production of domestic manufacturing and extractive industries was supplied to foreign consumers. Thus, according to the State Statistics Service of Ukraine, over the past 5 years the share of exports of goods and services in the GDP structure ranged from $56.4 \%$ to $52.2 \%$ (in actual prices). At the same time, there have been significant structural changes in export flows. The factors of these shifts were the lack of investments directed to the modernization of the industrial complex, rent-oriented behavior of oligarchic structures, offshore business organization. The absolute and relative advantages in international trade formed in this way provided enrichment of a limited group of stakeholders, and at the same time became the drivers of the systemic economic crisis and Ukraine's loss of the ability to adsorb (resilience respond) to shock disturbances.

\section{THEORETICAL APPROACHES}

In general system theory (GST), structural diversification plays a key role in ensuring the reliability of sustainable development of socio-economic systems. As already noted in our previous studies, GST has been successfully used in behavioral research environmental, social and economic systems (Burlutskiy et al, 2019)In this article we aim to demonstrate how GST can be used as a significant model for sustainable growth through structural diversification. Each system as a whole can be seen as an integral part of larger super-systems consisting of smaller subsystems, so that the entire system can is perceived as a hierarchical order of many different levels of structural expressions, each of which corresponds to the general, functional archetype of the system (Von Bertalanffy, 1968). All socio-economic systems are open systems, i.e. they keep a dynamic equilibrium by importing energy from outside, converting this energy in negentropy, and then throwing entropic energy back into the environment. The change in entropy under such conditions is determined by the production of entropy within the system due to irreversibility processes and the transfer of entropy outside the system. Dynamics of entropy in an open system as an additive function of the endogenous and exogenous component is illustrated by the I. Prigogine equation [Prigogine, 1957]. Within the framework of this analysis, the exogenous component corresponds to the export and import flows of the country. 
The export flow for its economic content characterizes the outflow of entropy, and the import the opposite of the inflow. This research vector is conceptually developed and supported by appropriate theoretical and methodological support, wide range of empirical research (Dilbaz Alacahan, 2017).

A fairly complete analysis of methodological tools for assessing structural factors of economic dynamics has been given in the latest publication by European Commission researchers Serenella Salaa, Biagio Ciuffob, Peter Nijkampc (Salaa et al, 2015). Most scholars have confirmed the validity of the conclusions regarding the negative impact of high concentration (low commodity diversification) of exports on the parameters of the economic response. A representative selection of countries were European Union and BRICS (Vahalik, 2015). Analysis of the impact of destabilizing factors on regional differences in development in the conditions of structural transformation crisis is devoted to the study of Yanjin Chen, Xiangmin Xiong (Chen and Xiong, 2014). Using statistics covering 31 regions of China, the impact of diversified exports on economic growth has been studied. Indicators such as per capita income, level of investment, human capital, and export intensity on the direct stimulates China's economic growth. The findings were supported by the economic performance of China's border and hinterland provinces. Ultimately, structural shifts in export flows are one of the key determinants of resiliency in response to shocks in both the national economy and the region. To evolve new paradigm, which includes a holistic, systems perspective it is necessary to accentuate: the problem of resilience of social and economic systems, as a reaction to internal and external disturbances in order to maintain its functionality and integrity, remains without attention of researchers.

As a result of the research of the 2008-2009 financial crisis's impact on Latin American exports, the IMF's budget specialists N. Costa Neto and R. Romeo identified certain significant dependencies (Costa Neto and Romeo, 1999): export diversity contributes to the country's productivity increase, and therefore, product diversification of trade can determine the consequences of the crisis. The crisis has a more negative impact on less productive production or industries. This allows us to hypothesize the possibility of a similar dependence on the domestic economy.

\section{METHODOLOGY}

The sharpness and strength of structural shifts depend on the volatility (variation) of absolute growth indicators and growth rates of the relative weight. The higher the volatility of absolute growth indicators, the sharper and stronger the absolute structural shifts; the higher the volatility of growth rates, the sharper and stronger the relative structural shifts are. Hence, the question arose as to the use of variation indicators, the variability of absolute growth indicators and the growth rates of the relative weight of the individual components of the whole under study for a generalized assessment of structural shifts.

The basis for the calculation of the composite indicators of relative structural shifts is the growth rate of the relative weights considered as part of the whole. The degree of its variation should be seen as the composite generalizing characteristic.

Let us consider a generalizing indicator of relative structural shifts based on the weighted average square deviation. It can be calculated using the following formula: 


$$
\sigma_{\frac{d 1}{d 0}}=\sqrt{\sum_{i=1}^{n} \frac{\left(d_{i 1}-d_{i 0}\right)^{2}}{d_{i 0}} \times 100},
$$

where $d_{i 1}, d_{i 0}$ - the relative weights of separate elements of two compared sets; $n$ - number of elements (groups) in the aggregate.

This indicator shows how much the growth factors (rates) of individual parts of the population deviate from their average value of one $(100 \%)$ on average, or, in other words, what is the average square value of the relative deviation of the relative weights.

Bulgarian statistician K. Gatayev proposed to normalize the linear and square coefficients of absolute structural shifts through division by its maximum possible value (Epps, 2013). The Gatayev index takes into account the intensity of changes in individual groups in the compared structures:

$$
K g=\sqrt{\frac{\sum_{i=1}^{n}\left(d_{i 1}-d_{i 0}\right)^{2}}{\sum_{i=1}^{n} d_{i 1}^{2}+\sum_{i=1}^{n} d_{i 0}^{2}}},
$$

The Szalai structural difference index (Szalai, 1972). This indicator also refers to the number of groups or elements in the structures being compared:

$$
K s=\sqrt{\frac{\sum_{i=1}^{n}\left(\frac{d_{i 1}-d_{i 0}}{d_{i 1}+d_{i 0}}\right)^{2}}{n}},
$$

Both submitted coefficients (or indices) can be from zero to one. The closer the value is to one, the more significant the structural changes that have occurred. The Szalai index takes on unit-like values in case of the total number of units is large.

To analyze the concentration of trade (export), an indicator similar to the HerfindahlHirschman Index is used (Epps, 2013). Export is divided into n groups, the share of Si (in percentage terms) of each group is square, and the concentration index is the sum of the obtained values (the maximum concentration level is 10000):

$$
I H H=\sum_{i=1}^{n} S_{i}^{2}
$$

This article uses data to examine the effects of trade (export) concentration and structural shifts as determinants of export volume in Ukraine between the years 2007 and 2014. The choice of this period is based on the data availability. Much of the data was taken from the Ukraine's Foreign Trade Indicators (2015). The 2015-2018 data were not used as the armed conflict in the East of Ukraine is a very strong factor distorting the patterns of the economy functioning in normal conditions.

\section{ANALYSIS AND RESULT}

The results of the conducted calculations (Fig.1) do not allow to identify the unconditional qualitative relationship between the export volumes and its commodity concentration. 
Figure.1. Dynamics of export volume and its concentration over 2007-2014 years in Ukraine

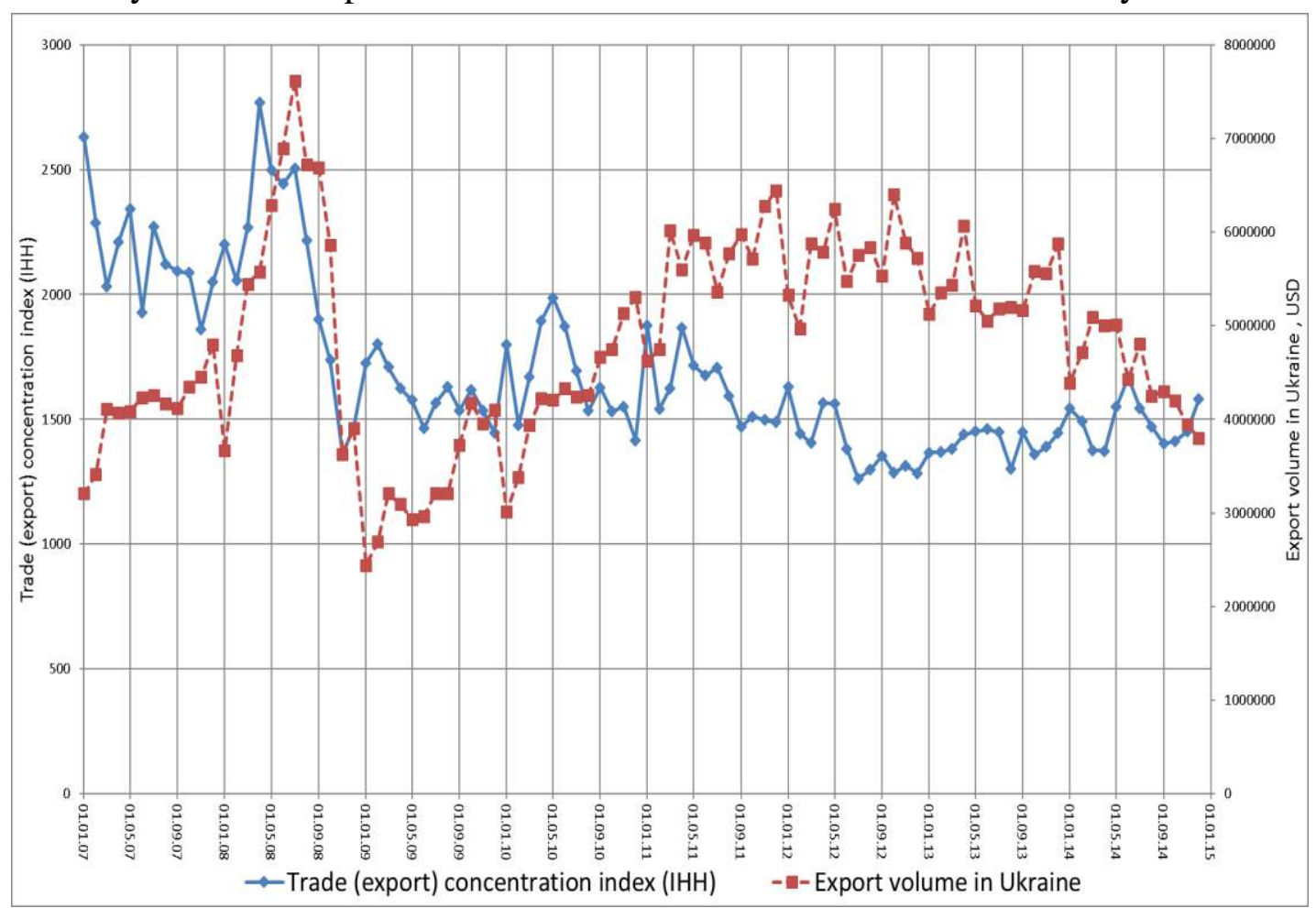

Source: authors calculations

In general, the high level of concentration in the pre-crisis period (maximum value of 2767,7 ) decreased to the level of 1300-1600 units in the post-crisis period. At the same time, there is a clearly defined lag ( 3 months) between the export volume and the concentration index. Taking into account the compensation of lagging lag (Table 1), such conclusions are correct:

Table 1. Indicators of structural shifts in the export flow for 2007-2014

\begin{tabular}{|c|c|c|c|c|c|}
\hline \multirow{2}{*}{\multicolumn{2}{|c|}{ Indicator }} & \multicolumn{4}{|c|}{ Period / Dynamics of the export turnover } \\
\hline & & \multirow{2}{*}{$\begin{array}{c}\text { Growth } \\
01.2007- \\
07.2008 \\
2629,9\end{array}$} & \multirow{2}{*}{$\begin{array}{c}\text { Fall } \\
07.2008- \\
01.2009 \\
2505,3\end{array}$} & \multirow{2}{*}{$\begin{array}{c}\text { Recovery } \\
01.2009- \\
12.2011 \\
1726,2\end{array}$} & \multirow{2}{*}{$\begin{array}{c}\text { Fall } \\
12.2011- \\
12.2014 \\
1487,4\end{array}$} \\
\hline \multirow{2}{*}{$\mathrm{IHH}$} & baseline & & & & \\
\hline & endline & 2505,3 & 1726,2 & 1487,4 & 1579,8 \\
\hline \multirow{2}{*}{$\begin{array}{l}\mathrm{IHH} \\
\text { (lag) }\end{array}$} & baseline & - & 2767,7 & 1736,2 & 1469,7 \\
\hline & endline & 2767,7 & 1736,2 & 1469,7 & 1401,1 \\
\hline \multirow[b]{2}{*}{$\sigma_{\mathrm{d} 1 / \mathrm{d} 0}$} & during the period & \multirow[b]{2}{*}{57.849} & 38,946 & 27,256 & 78,348 \\
\hline & $\begin{array}{c}\text { in comparison with } \\
01.2007\end{array}$ & & 92,752 & 91,620 & 208,706 \\
\hline \multirow[b]{2}{*}{$\mathrm{Kg}$} & during the period & \multirow[b]{2}{*}{0.112} & 0,194 & 0,153 & 0,323 \\
\hline & $\begin{array}{c}\text { in comparison with } \\
01.2007\end{array}$ & & 0,256 & 0,343 & 0,520 \\
\hline \multirow[b]{2}{*}{$\mathrm{Ks}$} & during the period & \multirow[b]{2}{*}{0.215} & 0,252 & 0,263 & 0,449 \\
\hline & $\begin{array}{c}\text { in comparison with } \\
01.2007\end{array}$ & & 0,269 & 0,328 & 0,452 \\
\hline \multirow[b]{2}{*}{$\mathrm{Kr}$} & during the period & \multirow{2}{*}{0.079} & 0,139 & 0,109 & 0,234 \\
\hline & $\begin{array}{c}\text { in comparison with } \\
01.2007\end{array}$ & & 0,184 & 0,250 & 0,395 \\
\hline
\end{tabular}

Source: authors calculations 
1) in the growth period $(01.2007$ - 07.2008), the export elasticity in terms of concentration is 11.89 , while the variation of the $\mathrm{IHH}$ index does not exceed $10.44 \%$. The obtained indicators are rather tentative, which is due to the fact that the data of previous periods were not taken into account, in which growth was also observed;

2) during the fall period (07.2008 - 01.2009) the concentration index decreased from 2767.7 to 1736.2 units (variation of $17.7 \%$ ), which determines the elasticity of exports at the level of 1.82. This indicates that the growth of the export concentration index (IHH) of products before the crisis by $1 \%$ (100 points) has led to an acceleration of the volume of export reduction in the conditions of the crisis by $1.82 \%$. Thus, the ultra-high concentration of exports (mainly due to the dominance of the article - "base metals and their products") has resulted in a shock impact of the global financial crisis on the domestic economy. During the same period, the growth of the index of trade and industrial concentration by one hundredth (with the basic weighted average level of 2200 units) has led to a decrease in exports by $0.47 \%$ for Latin America (Costa Neto and Romeo, 1999).

3) during the recovery period (01.2009 - 12.2011), the weighted average concentration index did not exceed the value of 1631,9 units (8.95\% variation), and the export elasticity was negative 4,37 units. As a consequence, the increased diversification of products contributed to the growth of exports. The maximum volume of exports after the recovery was $\$ 6443$ million. For comparison, the pre-crisis maximum was $\$ 7,616$ million. Growth of diversification was caused, first of all, not by the increase in the exports volume of minority commodity positions, but by the decrease in the share of dominant positions. In addition, over the four months from the crisis bottom, the concentration index has been increasing from the minimum values of 1359,9 to the maximum of 1801,2 units. The main reason was the higher rate of recovery of dominating positions over the minority ones.

4) The decline period (12.2011 - 12.2014) actually consists of two time intervals. Until the end of 2013, there were fluctuations in exports in the range of USD 5500 million. With a period of 5-6 months. Since the beginning of 2014, a rather rapid decline in exports started, which was caused by endogenous causes, in contrast to the fall of 2008 - the breakdown of the functioning of the industrial complex in Donetsk and Luhansk regions, problems in the monetary (credit) sectors of the economy. Overall, the export elasticity in terms of concentration was 10.8 units. The variation of the IHH index did not exceed $7.03 \%$, and the drop-in exports amounted to $40.9 \%$, compared to the maximum of December 2011. A certain increase in export concentration over the last four months of 2014 was a reflection of the almost double increase in the share of "plant-based products" (from 12.1\% to 24.9\%) in the export structure.

A set of integral indices is used to assess the significance of structural shifts in research practice. The following factors have been chosen within the framework of this analysis: the quadratic ratio of relative structural shifts $(\sigma \mathrm{d} 1 / \mathrm{d} 0)$, the integral coefficient of structural differences of Szalai (Ks), the integral coefficient of structural shifts of Gatayev and the indicator of relative differences in the structure $(\mathrm{Kr})$. The results of calculations of the quadratic ratio of relative structural shifts indicate rather significant changes in the structure of exports. In relative terms, during the reaction to the shock of 2008, the structure was varied by $92.752 \%$, and in the crisis period of 2014 - by $208.706 \%$. The Indicator of relative differences points to significant structural shifts during 2007-2013 and significant shifts in 2014. Similar conclusions can be obtained from the analysis of other integral ratios. In general, the scale of structural shifts in 2014 was much larger than in 2008. 


\section{CONCLUSIONS}

The conducted researches as a whole confirm the validity of the conclusions concerning the negative impact of high concentration (low commodity diversification) of exports on the parameters of the economy's reaction to shock disturbances. This conclusion is correct for both external and internal drivers of the crisis. The results of the analysis of the export determinants of social and economic resilience indicate the negative impact of "raw material" specificity on the ability of Ukraine to ensure constant development. The limited format of the article leaves unanswered the question related to the presence of a pre-leg between the dynamics of the level of concentration and the volume of exports. There is also a need for additional analysis of the relationship between export and import flows. It should also be noted that studies by N. Costa Neto and R. Romeo have empirically proven that the effects of the crisis have been mitigated through sectoral and product diversification of exports. In the case of the domestic economy, the first thesis finds its verification, but the neutrality of geographical diversification is quite disputable, which requires additional research in this direction. 


\section{REFERENCES}

BURLUTSKIY, S., BURLUTSKII Sv. and MARGASOVA, V., (2019), The Relationship Between Short-Term Fluctuations and Stages of Economic Cycle: The Case of Ukraine, Revista ESPACIOS, 40 (10), 10-21.

CHEN, Y., XIONG, X., (2014), An Empirical Analysis for Over-Sophisticated Export and Regional Economic Growth, Modern Economy, 5, 1114-1119.

EPPS, T., (2013), Probability and statistical theory for applied researchers. World Scientific Publishing Company, ISBN 978-9814513159.

NUR DİLBAZ ALACAHAN, YAĞMUR AKARSU, (2017), Foreign Trade Policy of European Union's Effects on Turkish Economy, Journal of Life Economics, 4(1), 2538.

PRIGOGINE, I., (1957), The Molecular Theory of Solutions, Amsterdam: North Holland Publishing Company.

RAFAEL ROMEU, NELSON CAMANHO DA COSTA NETO, (1999), Did Export Diversification Soften the Impact of the Global Financial Crisis?, IMF: Working Paper 11.

SERENELLA SALAA, BIAGIO CIUFFOB and PETER NIJKAMPC, (2015), A Systemic Framework for Sustainability Assessmen, Ecological Economics, 119, 314-325.

SZALAI, A. et al., (1972), The Use Of Time: Daily Activities Of Urban And Suburban Populations In Twelve Countries, Netherlands: The Hague Mouton.

VAHALIK, B., (2015), Analysis of Export Diversification Development of the European Union and BRICS Countries, Ekonomická revue -Central European Review of Economic Issues, 18, 59-69.

VON BERTALANFFY, L., (1968), General System Theory: Foundations, Development, New York: George Braziller, ISBN 978-0807604533. 